\title{
Melatonin attenuates inflammation, oxidative stress, and DNA damage in mice with nonalcoholic steatohepatitis induced by a methionine- and choline-deficient diet.
}

Fabiano Moraes Miguel

Universidade Luterana do Brasil

Jaqueline Nascimento Picada ( $\sim$ jnpicada@gmail.com )

Universidade Luterana do Brasil https://orcid.org/0000-0003-2360-1557

Juliana Bondan da Silva

Universidade Luterana do Brasil

Elizângela Gonçalves Schemitt

Universidade Federal do Rio Grande do Sul

Josieli Raskopf Colares

Universidade Federal do Rio Grande do Sul

Renata Minuzzo Hartmann

Universidade Federal do Rio Grande do Sul

Cláudio Augusto Marroni

Universidade Federal de Ciencias da Saude de Porto Alegre

Norma Possa Marroni

Universidade Federal do Rio Grande do Sul

Research Article

Keywords: cytokines, DNA damage, melatonin, mutagenicity, nonalcoholic steatohepatitis, oxidative stress

Posted Date: February 11th, 2022

DOI: https://doi.org/10.21203/rs.3.rs-1325195/v1

License: (9) (1) This work is licensed under a Creative Commons Attribution 4.0 International License. Read Full License 
Version of Record: A version of this preprint was published at Inflammation on April 13th, 2022. See the published version at https://doi.org/10.1007/s10753-022-01667-4. 


\section{Abstract}

Nonalcoholic steatohepatitis (NASH) is a disease with a high incidence worldwide, but its diagnosis and treatment are poorly managed. In this study, NASH pathophysiology and DNA damage biomarkers were investigated in mice with NASH treated and untreated with melatonin (MLT). C57BL/6 mice were fed a methionine- and choline-deficient (MCD) diet for four weeks to develop NASH. Melatonin was administered at $20 \mathrm{mg} / \mathrm{kg}$ during the last two weeks. Aspartate aminotransferase (AST) and alanine aminotransferase (ALT) levels were measured, and hepatic tissue was dissected for histological analysis, evaluation of lipoperoxidation, superoxide dismutase (SOD), catalase (CAT), and glutathione peroxidase (GPx), as well as nuclear factor-erythroid 2 (Nrf2), tumor necrosis factor alpha (TNF-a), inducible nitric oxide synthase (iNOS), and tumor necrosis factor alpha (TGF- $\beta$ ) expression by immunohistochemistry. DNA damage was evaluated using Comet assay, while a micronucleus test in bone marrow was performed to assess the genomic instability associated with the disease. Melatonin decreased AST and ALT, liver inflammatory processes, balloonization and fibrosis in mice with NASH, decreasing TNF- $a$, iNOS, and TGF- $\beta$, as well as oxidative stress, shown by reducing lipoperoxidation, and intensifying Nrf2 expression. The SOD and GPx activities were increased while CAT was decreased by treatment with MLT. Although the micronucleus frequency was not increased in mice with NASH, a protective effect on DNA was observed with MLT treatment in blood and liver tissues using Comet assay. As conclusions, MLT slows down the progression of $\mathrm{NASH}$, reducing hepatic oxidative stress and inflammatory processes, inhibiting DNA damage via anti-inflammatory and antioxidant actions.

\section{Introduction}

Nonalcoholic Steatohepatitis (NASH) is the most important clinical form of Nonalcoholic Fatty Liver Disease (NAFLD) which has increased worldwide at the similar rate as obesity [1]. NASH has a high incidence around 3 to $5 \%$ in patient with NAFLD and its progression can lead to more severe liver diseases such as cirrhosis and hepatocellular carcinoma [2,3]. The pathophysiology of NASH is complex and involves multiple factors. Insulin resistance appears to be the initial condition for the accumulation of fatty acids in the hepatocytes, since it favors lipogenesis and inhibits lipolysis, significantly increasing the input of fatty acids in liver, leading to progressive damage events with endoplasmic reticulum stress, mitochondrial dysfunction and chronic endotoxemia, resulting in hepatocellular lesion, inflammation, and fibrosis [4-6].

Concerning treatments for patients with NASH, weight loss and healthy eating are approaches suggested, however many patients fail to achieve weight loss goals and this way of handling it has proved inefficient. Few therapies have been sufficiently effective to avoid the progression or reversion of NASH therefore it is very necessary to develop specific treatments for this disease [7-10]. Melatonin (MLT) or Nacetyl-5-methoxytryptamine is a hormone produced mainly in the pineal gland and has shown important antioxidant action both in in vitro and in vivo studies, acting as a scavenger of free radicals, as well as indirectly modulating the activity of antioxidant enzymes $[11,12]$. Some studies have shown beneficial effects of melatonin on the liver in patients with NASH [13]. But some controversial responses of the 
treatment with MLT on biomarkers of liver damage remain to be elucidated [14-16]. A recent metaanalysis study of clinical trials in patients with NAFLD has shown that the treatment with MLT had no significant effect on alanine aminotransferase (ALT), but modulated the lipid-metabolism [17].

The experimental model of NASH induced by the methionine- and choline- deficient (MCD) diet was developed in rodents to reproduce the main characteristics of NASH in humans. The NASH model induced by MCD diet has been widely used to find alternatives for treatments of this disease, since it closely replicates the pathophysiology of $\mathrm{NASH}$, causing an increase in hepatic steatosis, leading to mitochondrial dysfunction by depletion of $\beta$-oxidation, overproduction of reactive oxygen species (ROS) and increasing pro-inflammatory cytokines, and fibrosis $[18,19]$. In addition, mice NASH induced by MCD diet showed increased DNA damage in liver [20]. In this sense, diseases associated with inflammatory processes might induce DNA damage in target tissues, leading to genomic instability which increases with the progression of these diseases [21,22]. It is known that cirrhotic rats have shown increased micronucleus frequency in bone marrow, which is a marker to assess genomic stability [23-25], but in the NASH model induced by MCD this biomarker remains to be analyzed.

The goal of this study is to assess biomarkers of DNA damage in C57BL/ 6 mice with NASH induced by MCD diet treated and non-treated with MLT, using the Comet assay in liver and blood and micronucleus in bone marrow. In addition, MLT hepatoprotection actions were evaluated, assessing characteristic endpoints of NASH, such as inflammatory lesions and severity of hepatic fibrosis using histopathological analyses, complemented by determination of aspartate aminotransferase (AST) and ALT enzymes in plasma, and evaluation of inducible nitric oxide synthase (iNOS), tumor necrosis factor alpha (TNF-a), transforming growth factor beta (TGF- $\beta$ ), and nuclear factor-erythroid 2 (Nfr2) expressions using immunohistochemical assays, and measurement of oxidative stress through lipoperoxidation and activity of superoxide dismutase (SOD), catalase (CAT), and glutathione peroxidase (GPx) antioxidant enzymes in liver.

\section{Materials And Methods \\ 2.1 Animals}

A total of 34 mice C57BL/ 6 aged 8 weeks weighing around $23 \mathrm{~g}$ was obtained from the Federal University of Pelotas, Brazil. The animals were kept in plastic cages, at a constant temperature of $22 \pm 4^{\circ} \mathrm{C}$, under a light/dark cycle of $12 \mathrm{~h}$. All experimental procedures were carried out in accordance with the national and international legislation (Guidelines of Brazilian Council of Animal Experimentation- CONCEA), with the approval of the Committee on the Ethical Use of Animals at ULBRA (authorization number 2015-4P).

\subsection{Experimental design}

The NASH induced by MCD diet was performed as described in previous studies [18, 26]. The MCD and control diets were purchased by the Brazilian company PragSoluções Biociências ${ }^{\circledR}$ (Antonio Carlos 
Nunes Tamanini Street, 315, Jaú, São Paulo, 17213000, Brazil) as described by Newberne et al. [27], with modifications [18].

The mice were randomly divided into 4 groups and fed ad libitum for 4 weeks ( 28 days) with MCD or control diet. The treatment with vehicle or MLT started from day 15, daily, for 2 weeks, according to the group: control (CO) group, animals fed with control diet that received vehicle, CO+MLT group, animals fed with control diet that received MLT, NASH group, animals fed with MCD diet that received vehicle, and $\mathrm{NASH}+\mathrm{MLT}$ group, animals fed with MCD diet that received MLT.

Melatonin (Sigma Chemical, St. Louis, USA) solution was prepared using a vehicle ( $1 \%$ ethanol in $0.9 \%$ $\mathrm{NaCl}$ ), daily, protected from light, and administered at $20 \mathrm{mg} / \mathrm{kg}$ body weight after $6: 00 \mathrm{p} . \mathrm{m}$. in the dark. The dose of MLT was chosen based on our previous studies [28-31]. Animals in the control groups received only vehicle. At the end of the experiment, the animals were weighed and anesthetized by intraperitoneal injection of a mixture of ketamine hydrochloride $(95 \mathrm{mg} / \mathrm{kg})$ and $2 \%$ xylazine hydrochloride $(8 \mathrm{mg} / \mathrm{kg})$ and euthanized by exsanguination.

\subsection{Preparation of homogenates}

Livers were excised, weighed, and immediately frozen at $-80^{\circ} \mathrm{C}$. The frozen tissues from each mouse were homogenized using $9 \mathrm{~mL}$ of ice-cold phosphate buffer $(\mathrm{KCl} 140 \mathrm{mM}$, phosphate $20 \mathrm{mM}$, pH 7.4) per tissue gram in Ultra Turrax for 40 seconds at $4{ }^{\circ} \mathrm{C}$ and centrifuged at $3000 \mathrm{rpm}$ for 10 min using a refrigerated centrifuge. The supernatants were separated and used for biochemical analysis [32].

\subsection{Protein}

The method of Bradford [33] was used to quantify proteins, with bovine albumin as the standard (SigmaAldrich, St. Louis, USA). The samples were measured spectrophotometrically at $595 \mathrm{~nm}$ and the concentrations expressed in $\mathrm{mg} / \mathrm{mL}$ to calculate thiobarbituric acid reacting substances (TBARS) and antioxidant enzyme activities.

\subsection{Plasma analyses}

Liver integrity was determined by evaluation of the plasma enzymes AST and ALT using the commercial kit Liquiform (Labtest Diagnóstica SA, Belo Horizonte, MG, Brazil).

\subsection{Histological analysis}

A specimen of liver was trimmed and fixed by immersion in $10 \%$ buffered formalin for $24 \mathrm{~h}$. The blocks were dehydrated in a graded ethanol series and embedded in paraffin wax. The paraffin blocks were cut with a microtome (Leitz ${ }^{\circledR} 1512$ ) to 3- $\mu$ m thickness sections. In the staining techniques, the slides were immersed in hematoxylin-eosin dyes for $5 \mathrm{~min}$, to evaluate injuries in the hepatic tissue analyzing them using a binocular microscope (Nikon Labophot, Tokyo, Japan). The images were captured with a magnification of $200 x$. 
Picrosirius staining was used to evaluate the degree of fibrosis by the presence of collagen. The qualitative analysis was performed using a binocular microscope (Nikon Labophot, Tokyo, Japan). The images were captured with a magnification of 200x. The percentage of fibrosis in the liver tissue was determined by a histomorphometric analysis in a microscope equipped with a digital camera and connected to an image capturing program Image-Plus software (Media Cybernetics ${ }^{\circ}$, Bethesda, USA). After analyzing 20 randomized fields per image, the ratios of conjunctive tissue relative to whole liver were calculated, the results appearing in pixels.

\subsection{Immunohistochemical evaluations}

Sections of liver in slides were dewaxed in xylol and hydrated through a gradient of ethanol. Antigen retrieval was performed in $10 \mathrm{mM}$ citrate, $\mathrm{pH}$ 6.0, by heating in a microwave oven for 25 minutes at 720 W. After cooling down at room temperature, endogenous peroxidase activity was blocked by exposure of the slides to $3 \%$ hydrogen peroxide in methanol for 15 minutes [34].

The slides were sequentially pre-incubated with $10 \%$ rabbit serum at room temperature to block possible unwanted reactions of the secondary antibody. The slides were incubated with polyclonal antibodies iNOS (SC-7271), Nrf2, TGF-TNF-a (SC-8301) (Santa Cruz Biotechnology®, Santa Cruz, CA, USA), dilution 1: 200 overnight at $4^{\circ} \mathrm{C}$. Afterwards, the slides were washed with buffer and incubated with anti-rabbit lgG biotinylated secondary antibody for 30 minutes at room temperature. Then the slides were treated with enVision ${ }^{\circledR}$ reagent and subjected to 3 washes with phosphate-buffered saline (PBS). The nuclei were counterstained with hematoxylin, and the primary antibody was diluted in PBS containing bovine albumin as a negative control.

The results were evaluated by one of the researchers, blinded to the groups, using a microscope equipped with a digital camera to capture images using Image-Plus software (Media Cybernetics $\AA$, Bethesda, USA).

\subsection{Lipoperoxidation in liver}

The amount of malondialdehyde generated by lipid peroxidation was measured by TBARS, a method that measures the amount of thiobarbituric acid reacting substances. Tissue samples were placed in test tubes with a mixture of $10 \%$ trichloroacetic acid (TCA) and $0.67 \%$ thiobarbituric acid (TBA). Subsequently, they were heated in a bath for 15 minutes and cooled on ice for about 5 minutes. After cooling the samples, $1.5 \mathrm{~mL}$ of n-butyl alcohol was added. Then, they were placed on a shaker for 45 seconds and centrifuged for 10 minutes at $3000 \mathrm{rpm}$. Finally, the dyed product, present in the upper fraction of the tubes, was read in a spectrophotometer with a $535 \mathrm{~nm}$ wavelength. The concentration of TBARS obtained was expressed in nmol per milligram of protein (Buege and Aust, 1978).

\subsection{Analyses of antioxidant enzymes}

The activity of the SOD enzyme is defined by its ability to inhibit a detection system that reacts with superoxide radical. The SOD measurement technique is based on the inhibition of this reaction with adrenaline, detected spectrophotometrically at $480 \mathrm{~nm}$. Data were expressed in SOD units per milligram 
of protein (USOD/mg prot.) [36]. The analysis of CAT activity is defined by the breakdown of hydrogen peroxide into water and oxygen, being directly proportional to its enzymatic activity, detected spectrophotometrically at $240 \mathrm{~nm}$. The results were expressed in pmoles per milligram of protein (pmoles/mg prot) [37]. Glutathione peroxidase activity can be studied by measuring the speed of NADPH consumption in the reduction of glutathione oxidase, detected spectrophotometrically at $340 \mathrm{~nm}$ and the results were expressed in nmoles per minute per milligram of protein (nmol/min/mg prot) [38].

\subsection{Alkaline comet assay}

Comet assay was carried out to evaluate DNA damage following the recommendation made by Tice et al. [39], with minor modifications [40] in samples of blood and liver. The blood samples (50 $\mu \mathrm{L})$ were transferred to heparin solution (Liquemine ${ }^{\circledR} 25000 \mathrm{UI}, 10 \mu \mathrm{L}$ ) and samples of liver were transferred to cold PBS at pH 7.4. Cell suspensions $(5 \mu \mathrm{L})$ were embedded in $95 \mu \mathrm{L}$ low melting point agarose $0.75 \%$ (GibcoBRL) and spread onto agarose-precoated microscope slides. After solidification, slides were placed in lysis buffer $(\mathrm{NaCl} 2.5 \mathrm{M}$, EDTA $100 \mathrm{mM}$, and Tris $10 \mathrm{mM}$, freshly added Triton X-100 1\%, and DMSO $10 \%, \mathrm{pH} 10)$ for $48 \mathrm{~h}$ at $4^{\circ} \mathrm{C}$. Then, the slides were incubated in freshly prepared alkaline buffer $(\mathrm{NaOH}$ $300 \mathrm{mM}$ and EDTA $1 \mathrm{M}, \mathrm{pH}>13$ ) for $20 \mathrm{~min}$ at $4{ }^{\circ} \mathrm{C}$ in an electrophoresis cube. An electric current of 300 $\mathrm{mA}$ at $25 \mathrm{~V}(0.90 \mathrm{~V} / \mathrm{cm})$ was applied for 15 minutes to induce DNA electrophoresis. The slides were then neutralized (Tris $0.4 \mathrm{M}, \mathrm{pH} 7.5$ ), stained with silver, and examined under an optical microscope. Images of 100 randomly selected nucleoids ( 50 nucleoids from each slide) from each animal were visually scored according to tail size into 5 classes, ranging from undamaged (0) to maximally damaged (4), resulting in a single DNA damage score for each animal, and consequently, for each group studied. Therefore, the damage index (DI) ranged from 0 (completely undamaged, 100 cells $\times 0$ ) to 400 (with maximum damage, $100 \times 4)$. Damage frequency (DF) was calculated based upon the number of nucleoids with a tail versus those with no tail.

\subsection{Micronucleus test in bone marrow}

Both femurs were collected from each mouse to perform the micronucleus test according to the US Environmental Protection Agency Gene-Tox Program guidelines [41]. Bone marrow from femurs was suspended in fetal calf serum and smears were prepared on clean glass slides. Slides were air-dried, fixed in methanol, stained in 10\% Giemsa and coded for a blind analysis. The incidence of MN was observed in 2000 PCE for each animal using bright-field optical microscopy at $1000 \times$ magnification. To avoid falsenegative results and obtain a value of bone marrow toxicity, the polychromatic erythrocyte/normochromatic erythrocyte (PCE/NCE) ratio was determined in 1000 cells [40].

\subsection{Statistical analysis}

The data from oxidative stress and inflammatory parameters were expressed as mean \pm standard error for each experimental group and analysis of variance (ANOVA) was used for statistical analysis followed 
by the Student-Newman-Keuls test for multiple comparisons. Comet assay and micronucleus test data were expressed as mean \pm standard deviation and evaluated using ANOVA followed by Tukey's test. The level of significance was at least $5 \%(p<0.05)$.

\section{Results}

Table 1 shows the levels of AST and ALT enzymes in the groups studied. The NASH group showed a significant increase in both enzymes $(p<0.05)$ in comparison with $C O$ and CO+MLT, while the NASH+MLT group showed a significant reduction $(p<0.05)$ in comparison with NASH.

Table 1

Aspartate aminotransferase (AST) and alanine aminotransferase (ALT) levels in the plasma of the studied groups. The data are expressed as the mean \pm standard error of the mean $(\mathrm{U} / \mathrm{L})$.

\begin{tabular}{|lllll|}
\hline Groups & CO & CO+MLT & NASH & NASH+MLT \\
\hline AST & $5.3 \pm 2.7$ & $4.39 \pm 1.1$ & $27.71 \pm 2^{*}$ & $11.1 \pm 1.8^{\#}$ \\
\hline ALT & $11.23 \pm 9.3$ & $6.67 \pm 5.3$ & $60.54 \pm 15.63^{*}$ & $32.75 \pm 9^{\#}$ \\
\hline$* p<0.05$ in comparison with CO and CO+MLT groups. ${ }^{*} \mathrm{p}<0.05$ in comparison with NASH group. \\
\hline
\end{tabular}

Histological analysis revealed hepatic damage in the NASH group with the presence of fat microparticles, a significant accumulation of fat macrovesicles, as well as hepatocellular balloonization, presence of inflammatory infiltrate, and a disruption of liver tissue, characterizing steatohepatitis (Fig. 1). On the other hand, the structure of the hepatic tissue showed preserved histological characteristics in the $\mathrm{CO}$ and $\mathrm{CO}+\mathrm{MLT}$ groups. The histological examination of the NASH+MLT group showed a reorganization of the hepatic parenchyma and reduction of steatosis, inflammation, and balloonization.

A significant increase of fibrosis was observed in the liver of the NASH group compared with $\mathrm{CO}$ and CO+MLT control groups ( $<<0.001$; Fig. 2), analyzed by collagen picrosirius staining, while a significant fibrosis reduction was detected in the NASH+MLT group in comparison with the NASH group $(p<0.01)$.

The NASH group showed Nrf2 expression lower than CO and CO+MLT $(p<0.01$; Fig. 3). A significant increase of Nrf2 was observed in the NASH+MLT group in comparison with the NASH group $(p<0.05)$. The TGF- $\beta$, TNF- $a$, and iNOS expressions increased significantly in the NASH group in comparison with $\mathrm{CO}$ and $\mathrm{CO}+\mathrm{MLT}(\mathrm{p}<0.001)$, while the NASH+MLT group showed lower expression levels of these biomarkers in comparison with the NASH group $(p<0.001)$.

A significant increase in TBARS was observed in the NASH group when compared to the controls $(p<$ 0.001) (Fig. 4), whereas the NASH+MLT group decreased TBARS significantly as compared to the NASH group ( $p$ 0.001). SOD and GPx activities in the NASH group were significantly lower in comparison with $\mathrm{CO}$ and $\mathrm{CO}+\mathrm{MLT}$ (Fig. 4), while in the NASH+MLT group a significant increase of both enzymes was observed in comparison with the NASH group. Conversely, CAT activity showed a significant increase in 
the NASH group in comparison with the control groups $(p<0.05)$ and a significant reduction in the NASH+MLT group when compared with the NASH group $(p<0.05)$.

Concerning genotoxic findings, Table 2 shows that both DI and DF values in the NASH group were significantly higher $(p<0.001)$ than of the CO group in the blood. In liver, the DI value was higher in the NASH group in comparison with the CO group. The NASH+MLT group showed significantly lower DI in comparison with the NASH group in both tissues. There were no significant differences in the micronucleus frequency and in the PCE/NCE ratio among the studied groups, excepting the positive control that showed increased MNPCE values as expected (Table 3).

Table 2

Comet assay in peripheral blood and liver of the studied groups. The data are expressed as the mean \pm standard deviation of the mean.

\section{Damage index Damage frequency}

Peripheral blood

$\begin{array}{lll}\text { CO } & 12.7 \pm 10.3^{\# \# \#} & 10.3 \pm 6.8^{\# \# \#} \\ \text { CO+MLT } & 12.9 \pm 5.1 \# \# \# & 11.9 \pm 4.9 \# \# \\ \text { NASH } & 67.0 \pm 18.2 * \star \star & 43.1 \pm 16.9 * \star \star \\ \text { NASH + MLT } & 37.3 \pm 13.4 \text { **\#\#\# } & 35.7 \pm 14.2 * \star\end{array}$

Liver

CO

$72.0 \pm 8.5^{\# \# \#}$

$58.2 \pm 6.0$

$\mathrm{CO}+\mathrm{MLT}$

$61.8 \pm 13.4$ \#\#

$51.8 \pm 8.2$

$\mathrm{NASH}$

$145.8 \pm 24.9 * \star *$

$60.6 \pm 10.4$

$\mathrm{NASH}+\mathrm{MLT}$

$101.5 \pm 27.3$ \#\#

$50.3 \pm 14.9$

$\mathrm{N}=5-8$ animals per group.

Damage index: can range from 0 (completely undamaged, 100 cells $\times 0$ ) to 400 (with maximum damage $100 \times 4)$.

Damage frequency: was calculated based on number of cells with tail versus those with no tail.

$\star \star \star ~ p<0.001$ in comparison with CO group. ${ }^{\# \#} p<0.01 ; \# \#$ p $<0.001$ in comparison with NASH group (ANOVA, Tukey's test). 
Table 3

Micronucleus test in bone marrow of the studied groups. The data are expressed as the mean \pm standard deviation of the mean.

\begin{tabular}{|c|c|c|}
\hline Group & MNPCE ${ }^{\mathrm{a}}$ in 2,000 PCE per animal & Ratio PCE/NCE ${ }^{b}$ in 1,000 erythrocytes per animal \\
\hline $\mathrm{CO}$ & $3.2 \pm 1.1$ & $2.8 \pm 0.4$ \\
\hline $\mathrm{CO}+\mathrm{MLT}$ & $2.0 \pm 0.7$ & $2.9 \pm 0.5$ \\
\hline $\mathrm{NASH}$ & $2.5 \pm 1.4$ & $2.6 \pm 0.3$ \\
\hline $\mathrm{NASH}+\mathrm{MLT}$ & $2.7 \pm 1.1$ & $2.4 \pm 0.2$ \\
\hline${ }^{\mathrm{c}} \mathrm{PC}$ & $11.0 \pm 2.6 * \star \star$ & $2.2 \pm 0.4$ \\
\hline \multicolumn{3}{|c|}{$\mathrm{N}=5-8$ animals per group. } \\
\hline \multicolumn{3}{|c|}{ a MNPCE: micronucleus in polychromatic erythrocytes. } \\
\hline \multicolumn{3}{|c|}{ b PCE/NCE ratio: polychromatic erythrocytes/normochromatic erytrocytes ratio } \\
\hline \multicolumn{3}{|c|}{${ }^{\mathrm{c}}$ Positive control (cyclophosphamide $40 \mathrm{mg} / \mathrm{kg}$, single dose i.p. $\mathrm{N}=3$ animals). } \\
\hline
\end{tabular}

\section{Discussion}

In this study the effects of MLT on NASH were assessed in an experimental model using C57BL/ 6 mice fed with a MCD diet, evaluating hepatic integrity, inflammatory processes, oxidative stress, and genotoxic/mutagenic effect markers. Marcolin et al. $[18,42]$ have shown that C57BL/ 6 mice, after 2 or 4 weeks fed with MCD, developed a NASH classical pathophysiological feature. Here, the animals were fed for 4 weeks and the treatment with MLT started 2 weeks after the beginning of the diets. NASH development was proved by evaluation of liver histopathological aspects, i. e., macrovesicular steatosis, hepatocellular ballooning, and fibrosis which already have been found in the previous studies [20,42]. The treatment with MLT attenuated the steatosis, ballooning and fibrosis, indicating hepatoprotection.

Regarding AST and ALT, the levels of these enzymes were significantly elevated in the NASH group compared to the controls, while the MLT-treated group showed significantly lower levels compared to the NASH group, corroborating a previous study [19]. Patients with NASH receiving MLT showed lower AST and ALT [13], however other studies did not find these enzymes altered by treatment with MLT [14, 17], indicating that other markers should be evaluated to assess MLT protection against steatohepatitis. In a study using English white pig with chronic steatohepatitis induced by a steatogenic diet, MLT was not able to decrease ALT, AST, and FA levels [16].

Pro-inflammatory cytokines are frequently increased in patients with NASH [14] and in experimental nonclinical models $[19,42]$ and might be used as liver markers in studies on steatohepatitis. In this study, 
the expression of TNF-a and iNOS increased in the NASH group, whereas in the MLT-treated group a significant reduction was observed, indicating an anti-inflammatory effect of MLT in this model, corroborating Tahan et al. [19] who have shown MLT decreased TNF-a, IL-1 $\beta$, and IL-6 using Wistar rats with steatohepatitis induced by MCD diet. Besides the inflammatory process, fibrosis is an important feature for the diagnosis of steatohepatitis, and it was shown by picrosirius staining and TGF- $\beta$ expression which were increased in the NASH group. The presence of fibrosis in the hepatic tissue happens by accumulation of extracellular collagen due to the inflammatory process $[43,44]$. In the NASH+MLT group there was a decrease in both hepatic fibrosis indicative parameters, showing that MLT inhibited the progression of liver damage. In another study, Bona et al. [28] have shown similar MLT action on pro-inflammatory markers and fibrosis (TGF- $\beta$ ) in a tetrachloride-induced cirrhosis model.

The accumulation of fat in hepatocytes stimulates Kupffer cells to release pro-inflammatory cytokines which exacerbate the formation of ROS, leading to oxidative stress [45]. In this sense, the NASH group showed an increase in lipoperoxidation which also has been associated as a possible mediator to liver fibrosis because it influences collagen synthesis [46]. In addition, GPX and SOD activities were reduced in the NASH group, while CAT increased, indicating a disbalance in antioxidant defenses due to oxidative stress triggered by hepatic steatosis. Previous studies have shown liver injuries due to oxidative stress in animals with NASH $[19,46,47]$ corroborating this study. The treatment with MLT decreased lipoperoxidation and increased GPx and SOD while it decreased CAT, likely due to its antioxidant effects with the ability to directly scavenge ROS and reactive nitrogen species (RNS) and indirectly modulate antioxidant enzymes [48]. In addition, MLT increased the Nrf2 expression which regulates the transcription of antioxidant responsive element (ARE) dependent genes to balance oxidative mediators and maintain cellular redox homeostasis [49-52]. Hence, the modulation of antioxidant enzyme activities as well as the decreased iNOS and TNF-a expressions were probably exacerbated by increased Nrf2 expression in mice with NASH treated with MLT, resulting in a decrease of oxidative stress.

Furthermore, the MLT treatment decreased DNA damage in blood and liver, likely due to its antioxidant and anti-inflammatory actions, diminishing ROS and RNS generation, avoiding the progression of NASH. Rezapoor et al. [53] have shown that MLT was able to increase the expression of genes related to DNA base excision repair (BER) such as Ogg1, Apex1, and Xrcc1 genes, which are associated with repair of free radical-induced DNA damage. It could explain the lower DI and DF in blood and liver cells using Comet assay. In the liver, a direct scavenger effect by MLT and its metabolites such as cyclic 3hydroxymelatonin, N1- acetyl-N 2-formyl-5-methoxyquinuramine (AFMK) and N1- acetyl-5methoxyquinuramine (AMK) might have contributed to protective effects on DNA, besides the indirect actions by increasing the DNA repair capacity. As observed in this study, MLT was able to decrease the expression of TNF- $\alpha$ and TGF- $\beta$ pro-inflammatory cytokines and iNOS, modulate antioxidant activities regarding CAT, SOD, and GPx and increase the expression of the Nrf-2, creating an adequate antiinflammatory environment to protect the genetic material as well as decreasing lipoperoxidation. This is the first study showing the ability of MLT to avoid DNA strand breaks in blood and liver cells of mice with NASH. In cirrhotic rats, MLT also decreased DNA damage in liver [23, 54]. Other compounds such as 
quercetin and simvastatin have shown similar responses in mice with NASH induced by the MCD diet, decreasing DNA damage in liver $[20,26]$.

DNA damage in blood was also observed in NASH mice, showing that the inflammation processes elicited in NASH might affect other tissues besides liver, although no increase in MNPCE in the NASH group was observed, showing that the bone marrow cells were not affected by the systemic injuries triggered by the disease. Conversely, in our previous studies, cirrhotic rats have not shown an increase in DNA damage in blood cells, but the MNPCE frequency increased [23-25]. These findings suggest that in the course of progression from NASH to cirrhosis the damaged blood cells could be removed or repaired, however the higher liver injuries in cirrhotic rats in comparison to NASH lead to systemic repercussions able to increase the genomic instability detected using the micronucleus test. It is known that, in the progression of hepatic diseases, other organs are gradually impaired, such as lung and skeletal muscles besides the liver, especially by inflammatory processes $[24,29,54,55]$.

Micronuclei are produced in dividing cells that contain breaks in chromosomes without centromeres and/or whole chromosomes which are unable to migrate to the poles during mitosis, and their presence in recently divided cells indicates genomic damage without the possibility of repair $[56,57]$. The chemical or physical clastogenic/aneugenic agents might increase the micronucleus frequency and are considered mutagenic agents. Furthermore, the association between aging and the reduction of antioxidant defenses and the increase in DNA repair deficiencies leading to higher MNPCE frequency is well known [22]. In a study to evaluate MLT on aging, Damiani et al. [58] have observed that MLT supplementation time is associated with DNA damage and micronucleus frequency that are lower in Swiss mice. Similarly, diseases involving an inflammatory process might increase the genomic instability detectable using the micronucleus test $[21,59,60]$. As already mentioned, no genomic instability was detected in the NASH model induced-MCD diet under conditions of the present study using micronucleus test in bone marrow, differently from other liver injury models such as cirrhosis induced by secondary bile duct ligation model [23-25], suggesting that genomic instability increases according to the progression of liver disease stages.

Since MNPCE frequency did not increase in the NASH group, no antimutagenic activity could be observed in the treatment with MLT. In a study to evaluate MLT protective effects against genotoxicity induced by ethanol in pregnant mice, antigenotoxic effects were shown, decreasing DNA damage in blood and liver. However, no antimutagenic activity was shown using the micronucleus test in bone marrow [61]. Other studies have shown antimutagenic effects of MLT such as reducing MNPCE frequency in mice treated with paraquat, a herbicide that generates free radicals [62]. Melatonin was also able to decrease DNA damage to blood, liver, and brain and micronucleus induced by exposure to pesticide cypermethrin in rat dams and offspring [63]. It decreased DNA damage in blood and micronucleus frequency in bone marrow of mice exposed to formaldehyde by inhalation [64]. Melatonin has prevented diabetes-related DNA damage of hepatocytes of rats treated for 4 weeks with low doses $(0.2 \mathrm{mg} / \mathrm{kg}$ at MTL) [65]. In addition, melatonin has shown anti-cancer $[66,67]$ and protective effects against carcinogens such as dimethyl 
bez (a) anthracene and diethylnitrosamine, reducing DNA damage evaluated using Comet assay in blood and liver cells of treated rats $[34,68]$, indicating its capacity to protect the genetic material.

\section{Conclusions}

The steatohepatitis that occurred using the MCD diet was not able to increase genomic instability assessed by micronucleus test which has been observed in the models of cirrhosis in rodents, emerging as one more alternative biomarker to evaluate liver disease severity. Melatonin exerted hepatoprotective effects on the NASH model by reducing oxidative stress, suppressing inflammation, and ameliorating the histopathological changes triggered by steatohepatitis, reducing lipid accumulation, fibrosis, and DNA damage in blood and liver. The findings suggest that MLT might inhibit the progression of NASH to cirrhosis, reinforcing its potential clinical application for the treatment of liver diseases.

\section{Abbreviations}

ALT: alanine aminotransferase

ANOVA: analysis of variance

AST: aspartate aminotransferase

CAT: catalase

GPx: glutathione peroxidase

iNOS: inducible nitric oxide synthase

MCD: methionine- and choline-deficient

MLT: melatonin

NASH: nonalcoholic steatohepatitis

NCE: normochromatic erythrocyte

Nrf2: nuclear factor-erythroid 2

PBS: phosphate-buffered saline

PCE: polychromatic erythrocyte

RNS: reactive nitrogen species

ROS: reactive oxygen species 
SOD: superoxide dismutase

TBARS: thiobarbituric acid reacting substances

TGF- $\beta$ : transforming growth factor beta

TNF-a: tumor necrosis factor alpha

\section{Declarations}

\section{Author Declarations}

\section{Ethics approval and consent to participate (Human Ethics, Animal Ethics or Plant Ethics)}

The procedures with the animals were submitted and approved with the protocol number 2015-4P in the evaluation by the Ethics Committee on the Animals Use (CEUA) at ULBRA. The procedures with the animals were carried out with accordance and recommendations of the CEUA and Federal Law No. 11,794 of October 8, 2008, that regulates the use of animals in scientific research in Brazil.

\section{Consent for publication}

This manuscript has been read and approved by all authors, and it has not been submitted for publication elsewhere.

Availability of data and materials. Not applicable

\section{Competing interests}

The authors declare that they have no known competing financial interests or personal relationships that could have appeared to influence the work reported in this paper.

\section{Funding}

Conselho Nacional de Desenvolvimento Científico e Tecnológico (Grant number: 301237/2018-2), Brazil. Dr. Norma Possa Marroni

\section{Authors' contributions}

Conceptualization: Dr. Norma Possa Marroni; Dr. Jaqueline Nascimento Picada; Methodology: Dr. Fabiano Moraes Miguel; Juliana Bondan da Silva, Dr. Elizângela Gonçalves Schemitt; Dr. Josieli Raskopf Colares; Dr. Renata Minuzzo Hartmann; Formal analysis and investigation: Dr. Fabiano Moraes Miguel; Writing - original draft preparation: Dr. Fabiano Moraes Miguel; Dr. Norma Possa Marroni; Dr. Jaqueline Nascimento Picada; Writing - review and editing: Dr. Norma Possa Marroni, Dr. Jaqueline Nascimento Picada, and Dr. Cláudio Augusto Marroni; Funding acquisition: Dr. Norma Possa Marroni; Supervision: Dr. Norma Possa Marroni and Dr. Jaqueline Nascimento Picada. 


\section{Acknowledgements}

This work was supported by Universidade Luterana do Brasil (ULBRA), Hospital de Clínicas de Porto Alegre (FIPE-HCPA), Universidade Federal do Rio Grande do Sul (UFRGS), Conselho Nacional de Desenvolvimento Científico e Tecnológico (Grant number: 301237/2018-2), Fundação de Amparo à Pesquisa do Estado do Rio Grande do Sul (FAPERGS), and Coordenação de Aperfeiçoamento de Pessoal de Nível Superior (CAPES; Finance Code 001), Brazil.

Authors' information (optional). Not applicable

\section{References}

1. Younossi, Z. M. 2019. Non-alcoholic fatty liver disease - A global public health perspective. Journal of Hepatology 70: 531-544. doi:10.1016/j.jhep.2018.10.033.

2. Manne, V., P. Handa, and K. V. Kowdley. 2018. Pathophysiology of Nonalcoholic Fatty Liver Disease/Nonalcoholic Steatohepatitis. Clinics in Liver Disease 22: 23-37. doi:10.1016/j.cld.2017.08.007.

3. Massoud, O., and M. Charlton. 2018. Nonalcoholic Fatty Liver Disease/Nonalcoholic Steatohepatitis and Hepatocellular Carcinoma. Clinics in Liver Disease 22: 201-211. doi:10.1016/j.cld.2017.08.014.

4. Lebeaupin, C., D. Vallée, Y. Hazari, C. Hetz, E. Chevet, and B. Bailly-Maitre. 2018. Endoplasmic reticulum stress signaling and the pathogenesis of non-alcoholic fatty liver disease. Journal of Hepatology 69: 927-947. doi:10.1016/j.jhep.2018.06.008.

5. Oseini, A. M., and A. J. Sanyal. 2017. Therapies in non-alcoholic steatohepatitis (NASH). Liver International: official journal of the International Association for the Study of the Liver 37 (Suppl 1): 97-103. doi:10.1111/liv.13302.

6. Younossi, Z., F. Tacke, M. Arrese, B. Chander Sharma, I. Mostafa, E. Bugianesi, V. Wai-Sun Wong, Y. Yilmaz, J. George, J. Fan, and M. B. Vos. 2019. Global Perspectives on Nonalcoholic Fatty Liver Disease and Nonalcoholic Steatohepatitis. Hepatology 69: 2672-2682. doi:10.1002/hep.30251.

7. Cusi, K. 2016. Treatment of patients with type 2 diabetes and non-alcoholic fatty liver disease: current approaches and future directions. Diabetologia 59: 1112-1120. doi:10.1007/s00125-0163952-1.

8. Lazaridis, N., and E. Tsochatzis. 2017. Current and future treatment options in non-alcoholic steatohepatitis (NASH). Expert Review of Gastroenterology \& Hepatology 11: 357-369. doi:10.1080/17474124.2017.1293523.

9. Musso, G., R. Gambino, M. Cassader, and G. Pagano. 2011. Meta-analysis: natural history of nonalcoholic fatty liver disease (NAFLD) and diagnostic accuracy of non-invasive tests for liver disease severity. Annals of Medicine 43: 617-649. doi:10.3109/07853890.2010.518623.

10. Teixeira, J., C. A. Marroni, P. R. Zubiaurre, A. Henz, L. Faina, L. K. Pinheiro, C. C. Mottin, and S. A. Fernandes. 2020. Phase angle and non-alcoholic fatty liver disease before and after bariatric surgery. 
World Journal of Hepatology 12: 1004-1019. doi:10.4254/wjh.v12.i11.1004.

11. Gonzalez, A., M. Estaras, S. Martinez-Morcillo, R. Martinez, A. García, M. Estévez, P. SantofımiaCastaño, J. A. Tapia, N. Moreno, M. Pérez-López, M. P. Míguez, G. Blanco-Fernández, D. Lopez-Guerra, M. Fernandez-Bermejo, J. M. Mateos, D. Vara, V. Roncero, and G. M. Salido. 2020. Melatonin modulates redox state and decreases viability of rat pancreatic stellate cells. Scientific Reports 10: 6352. doi:10.1038/s41598-020-63433-6.

12. Lebda, M. A., K. M. Sadek, T. K. Abouzed, H. G. Tohamy, and Y. S. El-Sayed. 2018. Melatonin mitigates thioacetamide-induced hepatic fibrosis via antioxidant activity and modulation of proinflammatory cytokines and fibrogenic genes. Life Sciences 192: 136-143. doi:10.1016/j.Ifs.2017.11.036.

13. Gonciarz, M., Z. Gonciarz, W. Bielanski, A. Mularczyk, P. C. Konturek, T. Brzozowski, and S. J. Konturek. 2012. The effects of long-term melatonin treatment on plasma liver enzymes levels and plasma concentrations of lipids and melatonin in patients with nonalcoholic steatohepatitis: a pilot study. Journal of Physiology and Pharmacology 63: 35-40.

14. Celinski, K., P. C. Konturek, M. Slomka, H. Cichoz-Lach, T. Brzozowski, S. J. Konturek, and A. Korolczuk. 2014. Effects of treatment with melatonin and tryptophan on liver enzymes, parameters of fat metabolism and plasma levels of cytokines in patients with non-alcoholic fatty liver disease-14 months follow up. Journal of Physiology and Pharmacology 65: 75-82.

15. Hardeland, R. 2019. Aging, Melatonin, and the Pro- and Anti-Inflammatory Networks. International Journal of Molecular Sciences 20: 1223. doi:10.3390/ijms20051223.

16. Martínez Soriano, B., A. Güemes, G. Pola, A. Gonzalo, P. Palacios Gasós, A. C. Navarro, R. MartínezBeamonte, J. Osada, and J. J. García. 2020. Effect of Melatonin as an Antioxidant Drug to Reverse Hepatic Steatosis: Experimental Model. Canadian Journal of Gastroenterology \& Hepatology 2020: 7315253. doi: $10.1155 / 2020 / 7315253$.

17. Mansoori, A., Z. Salimi, S. A. Hosseini, R. Hormoznejad, S. Jafarirad, M. Bahrami, and M. Asadi. 2020. The effect of melatonin supplementation on liver indices in patients with non-alcoholic fatty liver disease: A systematic review and meta-analysis of randomized clinical trials. Complementary Therapies in Medicine 52: 102398. doi:10.1016/j.ctim.2020.102398.

18. Marcolin, E., L. F. Forgiarini, J. Tieppo, A. S. Dias, L. A. Freitas, and N. P. Marroni. 2011. Methionineand choline-deficient diet induces hepatic changes characteristic of non-alcoholic steatohepatitis. Arquivos de Gastroenterologia 48: 72-79. doi:10.1590/s0004-28032011000100015.

19. Tahan, V., O. Atug, H. Akin, F. Eren, G. Tahan, O. Tarcin, H. Uzun, O. Ozdogan, O. Tarcin, N. Imeryuz, F. Ozguner, C. Celikel, E. Avsar, and N. Tozun. 2009. Melatonin ameliorates methionine- and cholinedeficient diet-induced nonalcoholic steatohepatitis in rats. Journal of Pineal Research 46: 401-407. doi:10.1111/j.1600-079X.2009.00676.x.

20. Marcolin, E., L. F. Forgiarini, G. Rodrigues, J. Tieppo, G. S. Borghetti, V. L. Bassani, J. N. Picada, and N. P. Marroni. 2013. Quercetin decreases liver damage in mice with non-alcoholic steatohepatitis. Basic \& Clinical Pharmacology \& Toxicology 112: 385-391. doi:10.1111/bcpt.12049. 
21. Andreassi, M. G., R. Barale, P. lozzo, and E. Picano. 2011. The association of micronucleus frequency with obesity, diabetes and cardiovascular disease. Mutagenesis 26: 77-83. doi:10.1093/mutage/geq077.

22. Fenech, M., S. Knasmueller, C. Bolognesi, N. Holland, S. Bonassi, and M. Kirsch-Volders. 2020. Micronuclei as biomarkers of DNA damage, aneuploidy, inducers of chromosomal hypermutation and as sources of pro-inflammatory DNA in humans. Mutation Research. Reviews in Mutation Research 786: 108342. doi:10.1016/j.mrrev.2020.108342.

23. Colares, J. R., R. M. Hartmann, E. G. Schemitt, S. R. B. Fonseca, M. S. Brasil, J. N. Picada, A. S. Dias, A. F. Bueno, C. A. Marroni, and N. P. Marroni. 2022. Melatonin prevents oxidative stress, inflammatory activity, and DNA damage in cirrhotic rats. World Journal of Gastroenterology 28: 348-364. doi:10.3748/wjg.v28.i3.348.

24. Tieppo, J., R. Vercelino, A. S. Dias, M. F. Silva Vaz, T. R. Silveira, C. A. Marroni, N. P. Marroni, J. A. Henriques, and J. N. Picada. 2007. Evaluation of the protective effects of quercetin in the hepatopulmonary syndrome. Food and Chemical Toxicology: an international journal published for the British Industrial Biological Research Association 45: 1140-1146. doi:10.1016/j.fct.2006.12.020.

25. Vercelino, R., J. Tieppo, A. S. Dias, C. A. Marroni, E. Garcia, L. Meurer, J. N. Picada, and N. P. Marroni. 2008. N-acetylcysteine effects on genotoxic and oxidative stress parameters in cirrhotic rats with hepatopulmonary syndrome. Basic \& Clinical Pharmacology \& Toxicology 102: 370-376. doi:10.1111/j.1742-7843.2007.00181.x.

26. Rodrigues, G., A. J. Moreira, S. Bona, E. Schemitt, C. A. Marroni, F. C. Di Naso, A. S. Dias, T. R. Pires, J. N. Picada, and N. P. Marroni. 2019. Simvastatin Reduces Hepatic Oxidative Stress and Endoplasmic Reticulum Stress in Nonalcoholic Steatohepatitis Experimental Model. Oxidative Medicine and Cellular Longevity 2019: 3201873. doi: 10.1155/2019/3201873.

27. Newberne, P. M., J. L. Camargo, and A. J. Clark. 1982. Choline Deficiency, Partial Hepatectomy, and Liver Tumors in Rats and Mice. Toxicologic Pathology 10: 95-106. doi:10.1177/019262338201000212.

28. Bona, S., G. Rodrigues, A. J. Moreira, F. C. Di Naso, A. S. Dias, Da Silveira, T. R. Marroni, C. A., and N. P. Marroni. 2018. Antifibrogenic effect of melatonin in rats with experimental liver cirrhosis induced by carbon tetrachloride. Journal of Gastroenterology and Hepatology Open 2: 117-123. doi:10.1002/jgh3.12055.

29. Colares, J. R., E. G. Schemitt, R. M. Hartmann, F. Licks, M. D. Soares, A. D. Bosco, and N. P. Marroni. 2016. Antioxidant and anti-inflammatory action of melatonin in an experimental model of secondary biliary cirrhosis induced by bile duct ligation. World Journal of Gastroenterology 22: 8918-8928. doi:10.3748/wjg.v22.i40.8918.

30. Ostjen, C. A., C. G. S. Rosa, R. M. Hartmann, E. G. Schemitt, J. R. Colares, and N. P. Marroni. 2019. Anti-inflammatory and antioxidant effect of melatonin on recovery from muscular trauma induced in rats. Experimental and Molecular Pathology 106: 52-59. doi:10.1016/j.yexmp.2018.12.001. 
31. Rosa, D. P., S. Bona, D. Simonetto, C. Zettler, C. A. Marroni, and N. P. Marroni. 2010. Melatonin protects the liver and erythrocytes against oxidative stress in cirrhotic rats. Arquivos de Gastroenterologia 47: 72-78. doi:10.1590/s0004-28032010000100013.

32. Llesuy, S. F., J. Milei, H. Molina, A. Boveris, and S. Milei. 1985. Comparison of lipid peroxidation and myocardial damage induced by adriamycin and 4'-epiadriamycin in mice. Tumori 71: 241-249.

33. Bradford, M. M. 1976. A rapid and sensitive method for the quantitation of microgram quantities of protein utilizing the principle of protein-dye binding. Analytical Biochemistry 72: 248-254. doi:10.1006/abio.1976.9999.

34. Moreira, A. J., R. Ordoñez, C. T. Cerski, J. N. Picada, A. García-Palomo, N. P. Marroni, J. L. Mauriz, and J. González-Gallego. 2015. Melatonin Activates Endoplasmic Reticulum Stress and Apoptosis in Rats with Diethylnitrosamine-Induced Hepatocarcinogenesis. PloS One 10: e0144517. doi:10.1371/journal.pone.0144517.

35. Buege, J. A., and S. D. Aust. 1978. Microsomal lipid peroxidation. Methods in Enzymology 52: 302310. doi:10.1016/s0076-6879(78)52032-6.

36. Misra, H. P., and I. Fridovich. 1972. The role of superoxide anion in the autoxidation of epinephrine and a simple assay for superoxide dismutase. The Journal of Biological Chemistry 247: 3170-3175.

37. Boveris, A., and B. Chance. 1973. The mitochondrial generation of hydrogen peroxide. General properties and effect of hyperbaric oxygen. The Biochemical Journal 134: 707-716. doi:10.1042/bj1340707.

38. Flohé, L., and W. A. Günzler. 1984. Assays of glutathione peroxidase. Methods in Enzymology 105 : 114-121. doi:10.1016/s0076-6879(84)05015-1.

39. Tice, R. R., E. Agurell, D. Anderson, B. Burlinson, A. Hartmann, H. Kobayashi, Y. Miyamae, E. Rojas, J. C. Ryu, and Y. F. Sasaki. 2000. Single cell gel/comet assay: guidelines for in vitro and in vivo genetic toxicology testing. Environmental and Molecular Mutagenesis 35: 206-221. doi:10.1002/(sici)10982280(2000)35:3<206::aid-em8>3.0.co;2-j.

40. De Sousa, J. A., L. D. S. Prado, B. L. Alderete, F. B. M. Boaretto, M. C. Allgayer, F. M. Miguel, J. T. De Sousa, N. P. Marroni, M. L. B. Lemes, D. S. Corrêa, A. B. F. Ferraz, and J. N. Picada. 2019. Toxicological aspects of Campomanesia xanthocarpa Berg. associated with its phytochemical profile. Journal of Toxicology and Environmental Health. Part A 82: 62-74. doi:10.1080/15287394.2018.1562392.

41. Mavournin, K. H., D. H. Blakey, M. C. Cimino, M. F. Salamone, and J. A. Heddle. 1990. The in vivo micronucleus assay in mammalian bone marrow and peripheral blood. A report of the U.S. Environmental Protection Agency Gene-Tox Program. Mutation Research 239: 29-80. doi:10.1016/0165-1110(90)90030-f.

42. Marcolin, E., B. San-Miguel, D. Vallejo, J. Tieppo, N. Marroni, J. González-Gallego, and M. J. Tuñón. 2012. Quercetin treatment ameliorates inflammation and fibrosis in mice with nonalcoholic steatohepatitis. The Journal of Nutrition 142: 1821-1828. doi:10.3945/jn.112.165274. 
43. Czechowska, G., K. Celinski, A. Korolczuk, G. Wojcicka, J. Dudka, A. Bojarska, and R. J. Reiter. 2015. Protective effects of melatonin against thioacetamide-induced liver fibrosis in rats. Journal of Physiology and Pharmacology 66: 567-579.

44. Kim, J. Y., J. H. Park, K. Kim, J. Leem, and K. K. Park. 2019. Melatonin Inhibits Transforming Growth Factor- $\beta 1$-Induced Epithelial-Mesenchymal Transition in AML12 Hepatocytes. Biology 8: 84. doi:10.3390/biology8040084.

45. Li, P., K. He, J. Li, Z. Liu, and J. Gong. 2017. The role of Kupffer cells in hepatic diseases. Molecular Immunology 85: 222-229. doi:10.1016/j.molimm.2017.02.018.

46. Zhang, L., H. X. Li, W. S. Pan, Ullah Khan, F. Qian, C. Qi-Li, F. R., and X. Xu. 2019. Administration of methyl palmitate prevents non-alcoholic steatohepatitis (NASH) by induction of PPAR-a. Biomedicine \& Pharmacotherapy 111: 99-108. doi:10.1016/j.biopha.2018.12.059.

47. Yahaghi, L., A. Ebrahim-Habibi, N. Hayati-Roodbari, S. Irani, and P. Yaghmaei. 2019. A simple method for inducing nonalcoholic steatohepatitis with fibrosis. Animal Models and Experimental Medicine 2: 282-290. doi:10.1002/ame2.12089.

48. Mortezaee, K., and N. Khanlarkhani. 2018. Melatonin application in targeting oxidative-induced liver injuries: A review. Journal of Cellular Physiology 233: 4015-4032. doi:10.1002/jcp.26209.

49. Chowdhry, S., M. H. Nazmy, P. J. Meakin, A. T. Dinkova-Kostova, S. V. Walsh, T. Tsujita, J. F. Dillon, M. L. Ashford, and J. D. Hayes. 2010. Loss of Nrf2 markedly exacerbates nonalcoholic steatohepatitis. Free Radical Biology \& Medicine 48: 357-371. doi:10.1016/j.freeradbiomed.2009.11.007.

50. Kim, E. H., M. R. Ridlo, B. C. Lee, and G. A. Kim. 2020. Melatonin-Nrf2 Signaling Activates Peroxisomal Activities in Porcine Cumulus Cell-Oocyte Complexes. Antioxidants 9: 1080. doi:10.3390/antiox9111080.

51. Li, Y., H. Yu, Z. Xu, S. Shi, D. Wang, X. Shi, Y. Wang, B. Zeng, H. Deng, X. Deng, and X. Zhong. 2019. Melatonin ameliorates ANIT-induced cholestasis by activating Nrf2 through a PI3K/Akt-dependent pathway in rats. Molecular Medicine Reports 19: 1185-1193. doi:10.3892/mmr.2018.9746.

52. Robledinos-Antón, N., R. Fernández-Ginés, G. Manda, and A. Cuadrado. 2019. Activators and Inhibitors of NRF2: A Review of Their Potential for Clinical Development. Oxidative Medicine and Cellular Longevity 2019: 9372182. doi: 10.1155/2019/9372182.

53. Rezapoor, S., A. Shirazi, S. Abbasi, J. T. Bazzaz, P. Izadi, H. Rezaeejam, M. Valizadeh, F. SoleimaniMohammadi, and M. Najafi. 2017. Modulation of Radiation-induced Base Excision Repair Pathway Gene Expression by Melatonin. Journal of Medical Physics / Association of Medical Physicists of India 42: 245-250. doi:10.4103/jmp.JMP_9_17.

54. Rosa, C. G. S., J. R. Colares, S. R. B. da Fonseca, G. D. S. Martins, F. M. Miguel, A. S. Dias, C. A. Marroni, J. N. Picada, M. Lehmann, and N. A. P. Marroni. 2021. Sarcopenia, oxidative stress and inflammatory process in muscle of cirrhotic rats - Action of melatonin and physical exercise. Experimental and Molecular Pathology 121: 104662. doi:10.1016/j.yexmp.2021.104662.

55. Scalon, D., J. N. Picada, J. T. de Sousa, A. T. da Silva, J. R. Colares, and N. A. P. Marroni. 2021. Photobiomodulation intervention improves oxidative, inflammatory, and morphological parameters 
of skeletal muscle in cirrhotic Wistar rats. Lasers in Medical Science. doi:10.1007/s10103-02103458-z.

56. Guo, X., J. Ni, Z. Liang, J. Xue, M. F. Fenech, and X. Wang. 2019. The molecular origins and pathophysiological consequences of micronuclei: New insights into an age-old problem. Mutation Research. Reviews in Mutation Research 779: 1-35. doi:10.1016/j.mrrev.2018.11.001.

57. Russo, A., and F. Degrassi. 2018. Molecular cytogenetics of the micronucleus: Still surprising. Mutation Research. Genetic Toxicology and Environmental Mutagenesis 836(Pt A): 36-40. doi:10.1016/j.mrgentox.2018.05.011.

58. Damiani, A. P., G. Strapazzon, T. T. de Oliveira Sardinha, P. Rohr, G. Gajski, R. A. de Pinho, and V. M. de Andrade. 2020. Melatonin supplementation over different time periods until ageing modulates genotoxic parameters in mice. Mutagenesis 35: 465-478. doi:10.1093/mutage/geaa017.

59. Asanov, M., S. Bonassi, S. Proietti, V. I. Minina, C. Tomino, and R. El-Zein. 2021. Genomic instability in chronic obstructive pulmonary disease and lung cancer: A systematic review and meta-analysis of studies using the micronucleus assay. Mutation Research. Reviews in Mutation Research 787: 108344. doi:10.1016/j.mrrev.2020.108344.

60. Deo, P., M. Fenech, and V. S. Dhillon. 2021. Association between glycation biomarkers, hyperglycemia, and micronucleus frequency: A meta -analysis. Mutation Research. Reviews in Mutation Research 787: 108369. doi:10.1016/j.mrrev.2021.108369.

61. Sousa Coelho, I. D. D., Lapa Neto, C. J. C. Souza, T. G. D. S. Silva, M. A. D. Chagas, C. A. Santos, K. R. P. D., Wanderley Teixeira, V., and A. A. C. Teixeira. 2018. Protective effect of exogenous melatonin in rats and their offspring on the genotoxic response induced by the chronic consumption of alcohol during pregnancy. Mutation Research. Genetic Toxicology and Environmental Mutagenesis 832-833: 52-60. doi:10.1016/j.mrgentox.2018.06.018.

62. Ortiz, G. G., r R. J. Reite, G. Zúñiga, D. Melchiorri, E. Sewerynek, M. I. Pablos, C. S. Oh, J. J. García, and O. K. Bitzer-Quintero. 2000. Genotoxicity of paraquat: micronuclei induced in bone marrow and peripheral blood are inhibited by melatonin. Mutation Research 464: 239-245. doi:10.1016/s13835718(99)00197-7.

63. do Nascimento Marinho, K. S., Lapa Neto, C. J. C. de Sousa Coelho, I. D. D. da Silva, M. A. Gomes Melo, M. E., Dos Santos, K. R. P. Chagas, C. A. Coelho Teixeira, A. A., and V. W. Teixeira. 2019. Genotoxic and mutagenic evaluation of the protective effect of exogenous melatonin in adult rats and their offspring exposed to the insecticides methomyl and cypermethrin during pregnancy. Mutation Research. Genetic Toxicology and Environmental Mutagenesis 848: 503107. doi:10.1016/j.mrgentox.2019.503107.

64. Bernardini, L., E. Barbosa, M. F. Charão, G. Goethel, D. Muller, C. Bau, N. A. Steffens, Santos Stein, C. Moresco, R. N. Garcia, S. C., Souza Vencato, M., and N. Brucker. 2020. Oxidative damage, inflammation, genotoxic effect, and global DNA methylation caused by inhalation of formaldehyde and the purpose of melatonin. Toxicology Research 9: 778-789. doi:10.1093/toxres/tfaa079. 
65. Grigorov, I., D. Bogojević, S. Jovanović, A. Petrović, S. Ivanović-Matić, L. Zolotarevski, G. Poznanović, and V. Martinović. 2014. Hepatoprotective effects of melatonin against pronecrotic cellular events in streptozotocin-induced diabetic rats. Journal of Physiology and Biochemistry 70: 441-450. doi:10.1007/s13105-014-0322-7.

66. Gurunathan, S., M. Qasim, M. H. Kang, and J. H. Kim. 2021. Role and Therapeutic Potential of Melatonin in Various Type of Cancers. Onco Targets and Therapy 14: 2019-2052. doi:10.2147/OTT.S298512.

67. Reiter, R. J., S. A. Rosales-Corral, D. X. Tan, D. Acuna-Castroviejo, L. Qin, S. F. Yang, and K. Xu. 2017. Melatonin, a Full Service Anti-Cancer Agent: Inhibition of Initiation, Progression and Metastasis. International Journal of Molecular Sciences 18: 843. doi:10.3390/ijms18040843.

68. Muqbil, I., S. Fatima, A. S. Azmi, A. S. Alsharidah, S. A. Khan, F. Aljaser, and N. Banu. 2020. Restraint stress abates the antioxidant potential of melatonin on dimethyl benz (a) anthracene (DMBA) induced carcinogenesis. Medical Oncology 37: 96. doi:10.1007/s12032-020-01422-5.

\section{Figures}
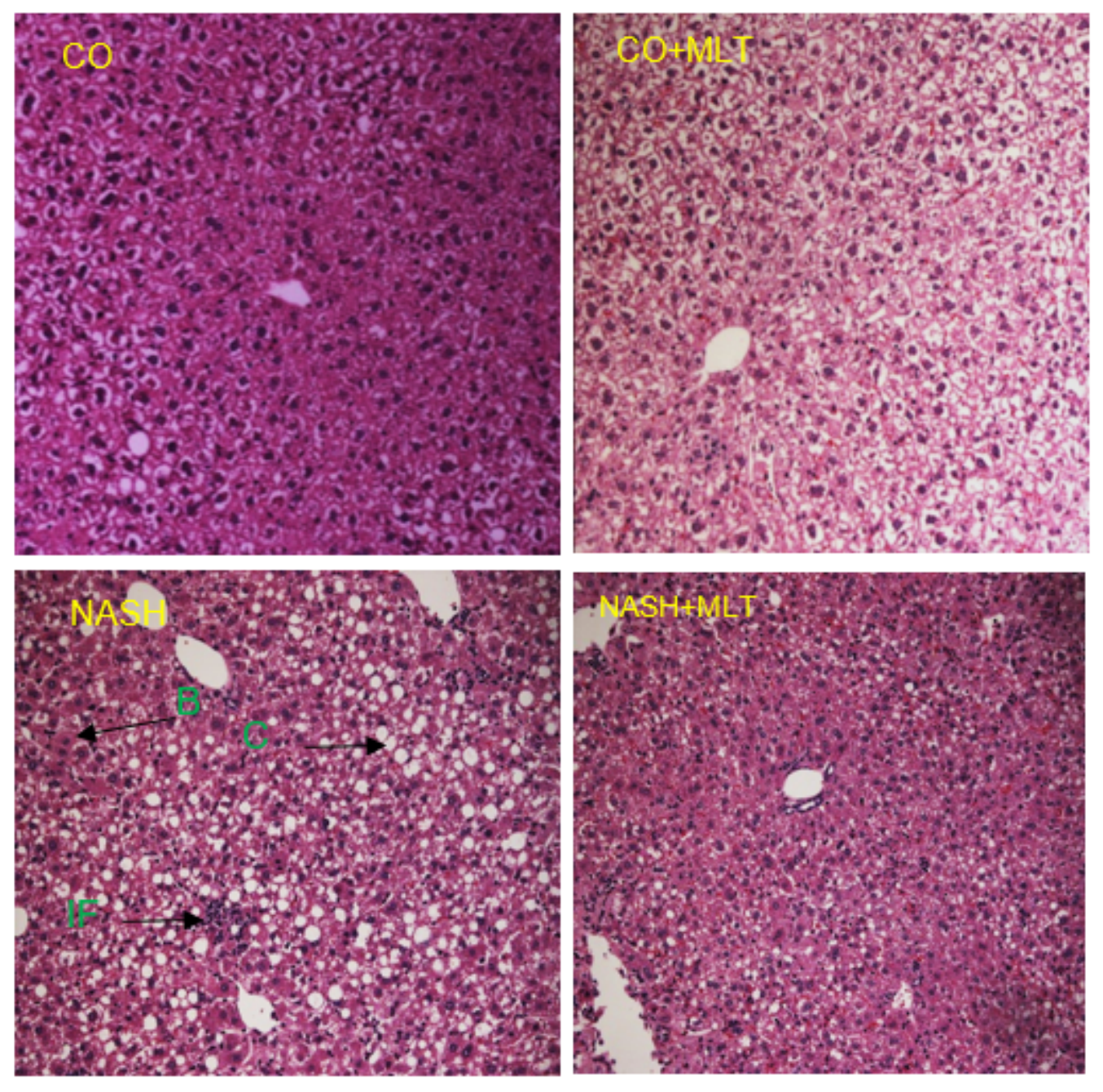

Figure 1 
Photomicrograph of hepatic tissue at $200 \times$ magnification in the different experimental groups. Hematoxylin-eosin staining to assess the liver parenchyma. In CO and CO+MLT groups, a normal liver parenchyma is observed. In the NASH group, the destruction of the parenchyma is noticed, with the presence of inflammatory infiltrate (IF), ballooning (B) and lipid macrovesicles (C). Parenchymal restructuring occurred in the NASH+MLT group.
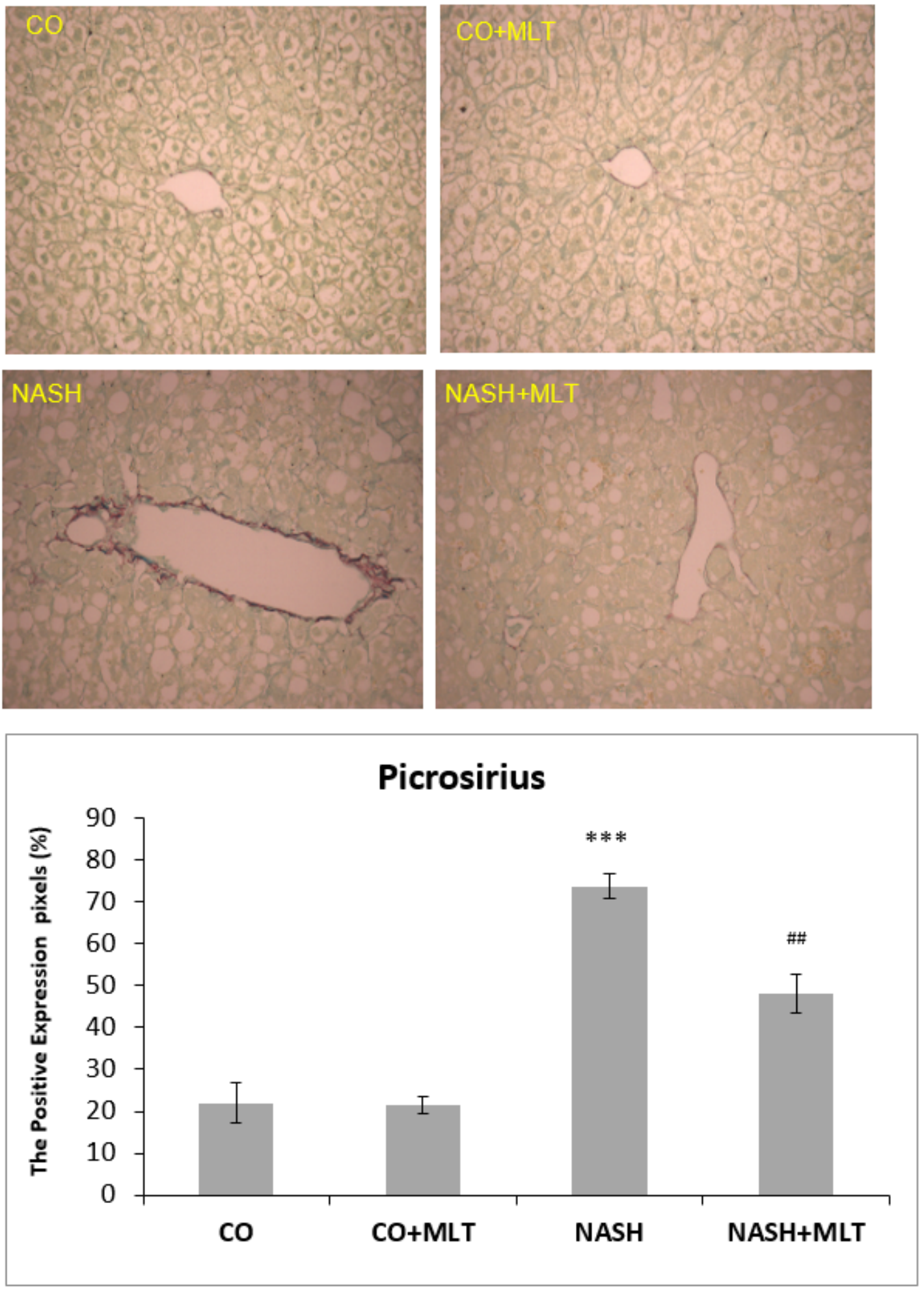
Figure 2

Photomicrograph of hepatic tissue at $200 \times$ magnification in the different experimental groups.

Picrosirius staining to assess liver fibrosis. Values are expressed as means \pm standard error of the mean ${ }^{\star * \star} \mathrm{p}<0.001$ in comparison with $\mathrm{CO}$ and CO+MLT groups. ${ }^{\# \#} \mathrm{p}<0.01$, in comparison with the NASH group.
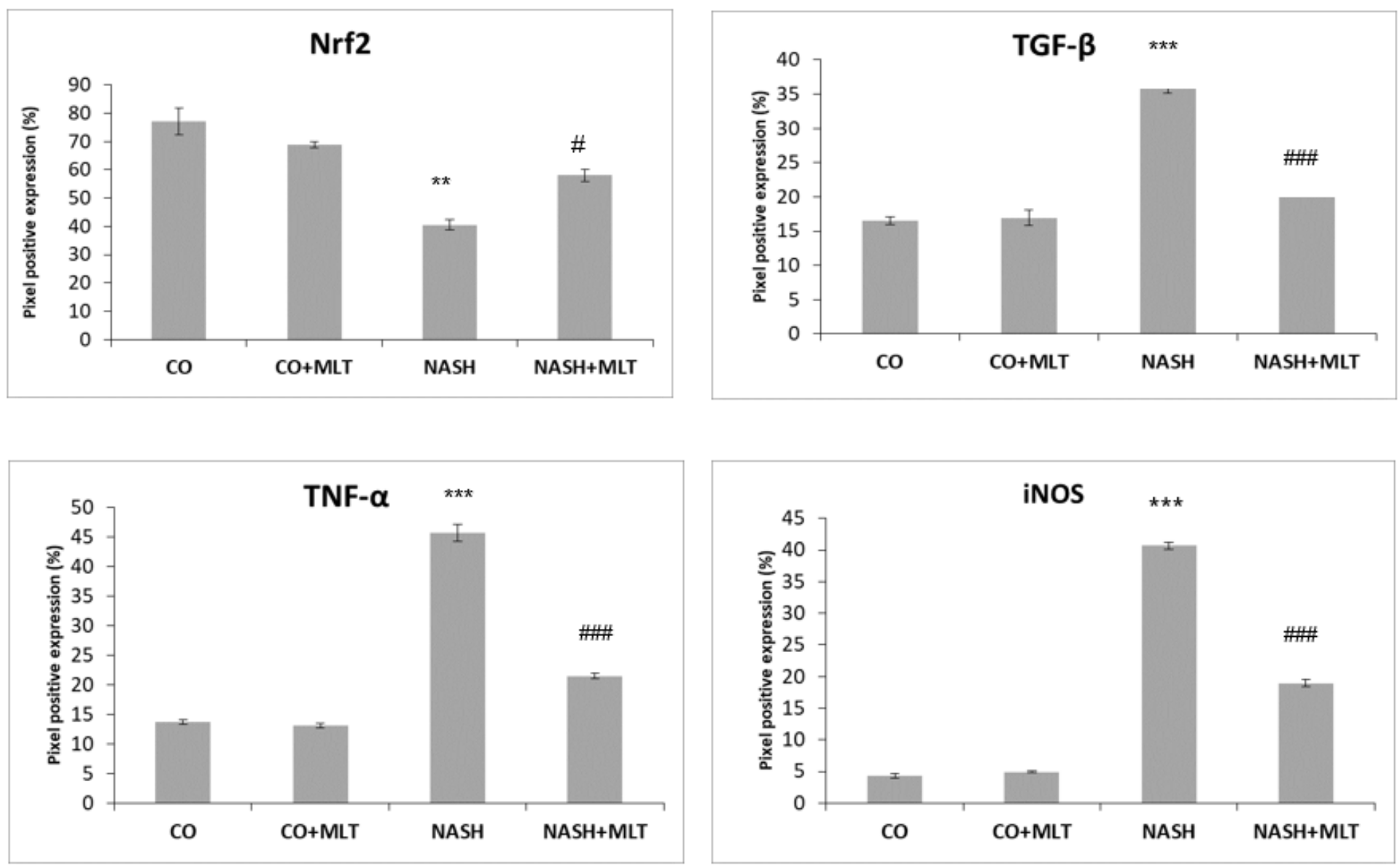

Figure 3

Nrf2, TGF- $\beta$, TNF- $\alpha$, and iNOS expressions (\% pixels) in the different experimental groups. Values are expressed as means \pm standard error of the mean. ${ }^{* *} p<0.01$, $* \star * p<0.001$ in comparison with $\mathrm{CO}$ and CO+MLT groups. ${ }^{\#} p<0.05,{ }^{\# \# \# ~} p<0.001$ in comparison with the NASH group. 

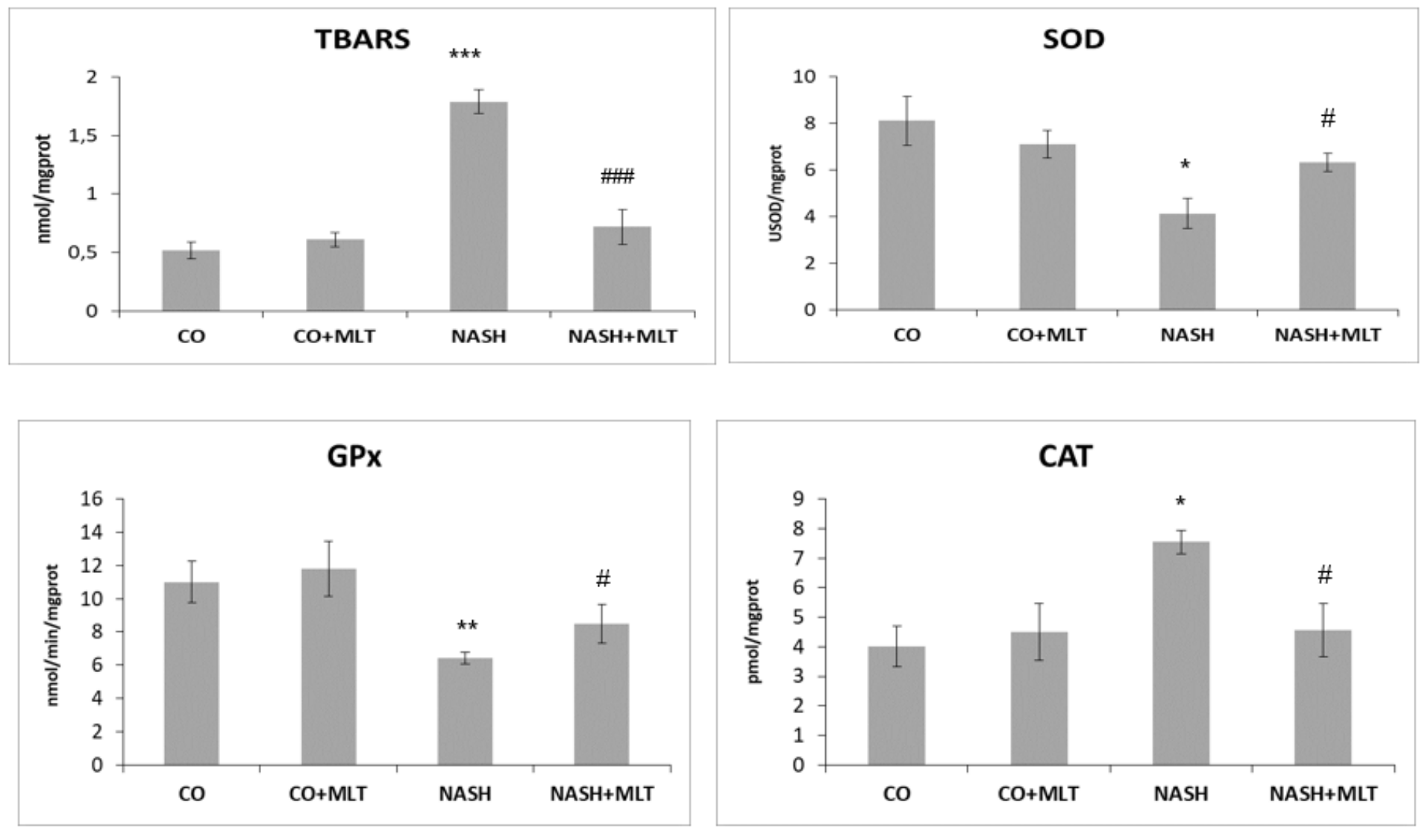

\section{Figure 4}

Lipoperoxidation by thiobarbituric acid reacting substances (TBARS) (nmol/mg prot), superoxide dismutase (SOD) activity (USOD/mg prot), glutathione peroxidase (GPx) activity ( $\mathrm{nmol} / \mathrm{min} / \mathrm{mg}$ prot), and catalase (CAT) activity (pmol/mg prot) in the different experimental groups. Values are expressed as means \pm standard error of the mean. ${ }^{*} p<0.05 ; * \star p<0.01 * \star \star p<0.001$ in comparison with $\mathrm{CO}$ and CO+MLT groups. ${ }^{\#} \mathrm{p}<0.05,{ }^{\# \# \#} \mathrm{p}<0.001$ in comparison with the NASH group. 